УДК 009:004.9

\title{
A Decade in Digital Humanities
}

\author{
Melissa Terras* \\ University College London \\ London, UK
}

Received 15.02.2016, received in revised form 07.05.2016, accepted 09.06.2016

The paper reviews the meaning and development of digital humanities giving the ex-amples of work published in various DH areas. The paper discusses what using these technologies means for the humanities, giving recommendations that can be useful across the sector.

Keywords: digital humanities, UCL Centre for Digital Humanities, Innovation Curve.

DOI: 10.17516/1997-1370-2016-9-7-1637-1650.

Research area: culture studies.

I decided to call my paper "A Decade in Digital Humanities" for three reasons:

1. The term Digital Humanities has been commonly used to describe the application of computational methods in the arts and humanities for 10 years, since the publication, in 2004, of the Companion to Digital Humanities ${ }^{1}$. "Digital Humanities" was quickly picked up by the academic community as a catch-all, big tent ${ }^{2}$ name for a range of activities in computing, the arts, and culture. A decade on from the publication of this seminal text, I thought it would be useful to reflect on the growth, spread, and changes that had occurred in our discipline, and my place within them.

2. This year sees me in my 12 th year of being in an academic post. I joined UCL in August 2003, my first academic post after obtaining my doctorate, and since then have worked my way up the ranks from probationary lecturer, to senior lecturer, to reader, and now full professor. The paper gives me a rare chance to pause and look behind me to see what the body of work built up over this time represents.

3. You'll have to wait for later in the paper to see the third reason...

Who here would be comfortable defining what is meant by the term Digital Humanities ${ }^{3}$ ? This paper is also related to the week of UCL Festival of the Arts, celebrating all things to do with the Arts and Humanities at my home institution, which gives us an opportunity to look back to first principles. In UCLDH and 4Humanities' award winning infographic "The Humanities Matter" we defined the humanities as "academic disciplines that seek to understand and interpret the human experience, from individuals to entire cultures, engaging in the discovery, preservation, and communication of the past and present record to enable a deeper understanding of contemporary society." It stands to reason, then, that the Digital Humanities are computational

(C) Siberian Federal University. All rights reserved

* Corresponding author E-mail address: m.terras@ucl.ac.uk 
methods that are trying to understand what it means to be human, in both our past and present society. But it may be easier if I give some brief examples to demonstrate the kind of work we Digital Humanists get up to, or rather, the kind of work I, as a self-confessed, and now be-titled Digital Humanist, get up to ${ }^{5}$.

One of the easiest things we can do with computers is count things. For data to be computationally manipulated, it has to be in numeric form. If we can get text into a computational form, we can easily count and manipulate the language, showing trends across time. For example, if we take a million words of conference abstracts from my discipline from the ALLC/ACH conference across various years, we can easily see how mentions of one technology (XML) becomes more popular, while another (SGML) is in decline ${ }^{6}$. Much of the work in $\mathrm{DH}$ is in manipulating and processing and analysing text - our iOS app Textal is just part of that trajectory ${ }^{7}$. Much of $m y$ work, though, has been in digital images, starting with developing systems to try and read damaged documents from Hadrian's wall ${ }^{8}$, and more recently working on multispectral ${ }^{9}$ and 3D manipulation of damaged texts $^{10}$. We've also worked with museums on large scale 3D capture of cultural and heritage objects. The important thing about all of this is that as well as implementation, we're also interested in use and usage ${ }^{11}$ of these technologies, and what impact that they have on those working in culture and heritage, and the ability to study the past and present human record. We often innovate new systems, or adopt concepts and apply them to humanities projects, such as the crowdsourcing of Jeremy Bentham's handwriting by volunteers ${ }^{12}$, or working with visitors to the Grant Museum of Zoology at UCL ${ }^{13}$ to encourage debate about zoological collections. We build, we test, we reflect back on what using these technologies means for the humanities, giving recommendations which can be useful across the sector. From these projects, its difficult to pin down what Digital Humanities actually is, but that sums up the difficulty of our discipline's title: it encourages thinking about computational methods in the arts and humanities, and then into culture and heritage, in as broad a sense as possible.

What made Digital Humanities spring, fully formed like Athena from the Head of Zeus, as an academic field in 2004? Was it because that was the first time quantifiable methods had been used in the Arts and Humanities? (remember - all computational methods require quantification). Well, of course that is nonsense. When you look back across the history of Humanities scholarship, quantifiable methods were used in the Arts and Humanities since the start of Humanities scholarship, having a history that stretches back to Antiquity ${ }^{14}$. If we think of the book as technology, from its inception scholars took it to pieces to see under the hood: concordances and indexes of works were manually created, such as this "Concordance or table made after the order of the alphabet ${ }^{15}$ " from 1579 which lists how many times concepts such as "abomination" appear in the New Testament. Or the work of Joseph Scaliger ${ }^{16}$ who in the early 1600 s plotted the different periods in time in which different civilizations must have existed, through quantifiable methods, showing that the Ancient Egyptians must have lived before the events described in the Old Testament. Or the work of August Schleicher in the 1850s who showed, by quantifiable methods, that the languages of Europe must have had a common historical root $^{17}$. All of these texts are available from UCL Library. Digitisation! Changing humanities scholarship! but the point is that quantifiable methods are part of established methods in the humanities, and have been for as long as the Humanities have existed. So when I undertook my first project at 
UCL, looking at whether we could use the high performance computing facilities at UCL to analyse historical census data ${ }^{18}$ - this is part of an quantifiable humanities academic tradition which harks back 500 years, just at a grander scale, given the affordances of the computational methods available to us.

So what made Digital Humanities spring, fully formed like Athena from the Head of Zeus, as an academic field in 2004? Perhaps in 2004, this was the first time people had used computational techniques in the arts and humanities? But of course, that is nonsense too. When you look back at the history of computing - and not even digital computing, but the very first computer - the very first computer programmer, Ada Lovelace, hints at the possibilities for art, music, and understanding human knowledge and culture in her earliest writings ${ }^{19}$. She understood that there was something more to the mathematical calculations afforded by this machine than science (she talks about possibilities for art, music, and understanding human nature), and they called her a madwoman for $i^{20}$. Well, this madwoman has a (yet totally unproven) theory that if you look at the history of the first 100 electronic programmable computers in the 1950s, 1960s and 1970s across the world, you will see humanists eyeing them up and asking "how can I use, or develop this tool for use, in my research"? It's certainly true of Father Busa ${ }^{21,}$ working with IBM in the $1950 \mathrm{~s}$ on the concordance of the works of Thomas Aquinas ${ }^{22}$ (counting, indexing, and manipulating words, as part of the historical trajectory of humanities methods stretching back 500 years, just a change in scale...) but also of Roy Wisbey, in Cambridge, who set up the Literary and Linguistic Computing Centre there in the $1960 \mathrm{~s}^{23}$. When the first computers arrived at UCL, the artists from the Slade School of Fine Art were over there like a shot to establish the Experimental and Computing Department ${ }^{24}$.
We should also mention Susan Hockey, who led various initiatives in text encoding, text analysis, and digital libraries in the 1970s, 1980s, and $1990 \mathrm{~s}^{25}$. Susan, incidentally, gave me my first academic job at UCL in 2003: UCL had included a Digital Resources in the Humanities module course as part of its MA offering for librarians and archivists in the School of Library, Archive and Information Studies (now the Department of Information Studies) from 2000, under Susan's auspices, demonstrating interesting relatively early links between library science and the field that is now DH. But the point is, considering how best to use computing in the arts and humanities is not something which started in the 21st Century, nor 2004, and Humanists have been looking at available tools, and how best to use them, since computation began. So when we undertook one of the latest projects at UCLDH, which came from looking at an iPhone, thinking "how can I use, or develop this tool for use, in my research in the Humanities" and developed an iOS app for text analysis, this is part of a longer trajectory of considering available computational tools, and how they may be appropriated, adopted, and adapted for our means in the humanities, just at a grander scale, as processing technologies increase in speed, scope, format, and availability.

So why Digital Humanities, in 2004? Firstly, the coalescing of interested scholars into an identifiable field is an understandable academic response to societal changes. The speed of computing processing rises, the price of computing plummets, the information available on the internet (and the possibility to create new information) increases, use and usage of internet technologies has become commonplace ${ }^{26}$. Remember, it's up to Humanities scholars to look at the past and present record to enable a deeper understanding of contemporary society: quite frankly, it would be more alarming if an 
academic movement hadn't emerged looking at what using computational methods could do for our understanding of human society, both past and present, and how best we can grab the technical opportunities which fly by and appropriate them for our means, to inform both ourselves and others about the prospects of using computing in this area. The discipline of Digital Humanities is inevitable, and would have appeared whatever the title it was given.

Secondly, Digital Humanities is a handy, all inclusive, modern title which rebrands all the various work which has gone before it, such as Humanities Computing, Computing and the Humanities, Cultural Heritage Informatics, Humanities Advanced Technology ${ }^{27} \ldots$ DH has a ring to this, and what a rebranding it was. We tend to call it "Big Tent Digital Humanities" meaning: roll up! roll up! everyone using any computational method in any aspects of the arts and humanities is welcome ${ }^{28}$ ! but really, Big Wave Digital Humanities may be more appropriate, as we countenance the sudden swell, dissipation, and speed of the activities of the discipline. Taking a peek at the mention of Digital Humanities on Google Ngrams we can see its sudden growth, and the fact that it is now used as a proper noun, with Capital Letters (although remember that this, counting words, is part of a long tradition of humanities scholarship, Google simply have more books to include in their count). We can see how DH has trended over time, appearing in headlines in the media. Many, many textbooks in DH appear, some of which I am responsible for myself ${ }^{29}$. Journals appear, such as Digital Humanities Quarterly (of which I'm one of the general editors), and the ALLC/ACH conference renames itself Digital Humanities (I was the Program Chair for DH2014 ${ }^{30}$ which was held in Lausanne, Switzerland). We saw over 700 proposals from more than 2000 authors vying for a space to present, and more than 750 attendees at the conference itself). There are many more DH conference presentations and workshop slots, worldwide, year on year ${ }^{31}$ In 2010, I gathered together all the available evidence I could on DH in an infographic called Quantifying Digital Humanities $^{32}$, showing that there were $114 \mathrm{DH}$ Centres in 24 countries. Today, there are $195 \mathrm{DH}$ Centers in 27 Countries. Those knowing how long it takes to set up a research centre know that this is phenomenal growth in the university and GLAM sector, and that institutional support must be strong, behind each and everyone of these.

UCL Centre for Digital Humanities is part of those who have joined the recently founded centres. However, in those five years since launch we've undertaken a phenomenal amount of projects, covering many aspects of Humanities and Arts research, and considered Digital Humanities in its broadest sense. There is an amazing team who are part of the Centre, and we've won variousawards for our academicprojects and collaborations, published many books, papers, and book chapters, featured in a range of popular media and press, and been part of successful funding bids from research councils worth tens of millions of pounds. One wonders, given the range and scope of work we've undertaken over the past five years, what makes a Digital Humanities Centre attractive to universities that don't have one.

As many DH centres spring up worldwide, what proportion of Humanities scholars are now digital humanists? Back in 2005, participants in the Summit on Digital Tools in the Humanities at the University of Virginia estimated that "only about six percent of humanist scholars go beyond general purpose information technology and use digital resources and more complex digital tools in their scholarship"33. By 2012, N. Katherine Hayles estimates that 10 per cent of Humanists are now digital humanists ${ }^{34}$. In 2014, a study from Ithaka S+R entitled Sustaining the Digital 
Humanities: Institutional Strategies beyond the Start-up Phase ${ }^{35}$ includes surveys of faculty at four American universities. In the departments surveyed at each institution, nearly $50 \%$ of faculty members indicated they have "created or managed" digital resources. Granted, the departments were chosen by campus staff (often at the library) who felt there was some significant activity taking place there. The percentage of these "creators" was consistent across all universities (Brown, Columbia, University of Wisconsin, University of Indiana), and most of the creators also felt that their creation was intended for public use (not just their own research aims), and would require ongoing development in the future.

$50 \%$ of humanists are involved in digital activity, are digital humanists. How can this possibly be? And how can we conceptualise what it means to be a digital humanist, amongst this spread of activity and range of available technology: is creating or managing digital resources the same as being a digital humanist? At a time where (nearly) every library catalogue is digitised and available online, and (nearly) every book manuscript written on a work processor, and many historical documents digitised and available for consulting from your own sofa, does that make everybody working in the humanities a digital humanist? How can I begin to conceptualise my contribution, and my place, and where my work sits within Big Wave Digital Humanities?

I find it useful, here to turn to Roger's Innovation Adoption Curve, a sociological model first proposed in the nineteen-sixties ${ }^{36}$ that looks at how technology spreads through society. This is a bell curve, and right at the start of adoption of technology, are a few innovators, experimenting (and developing) new technology. These innovators sometimes persuade a larger number of early adopters to take up the new technology on offer, and only once a sufficient mass of users are achieved, does the technology "cross the chasm" and become used by the majority of individuals in a society (who are split into an early majority, or late majority). Finally, we have adoption by the "laggards", who are slow in taking up technologies, but do so if they have permeated throughout society. (Hard not to think, here, of my elderly grandmother who recently got her first mobile phone). Now, this model is useful as we can plot along it some of the technologies which are available to a humanist. Things like word processing, and searching for references online, and even looking up the digitised texts: even the technologically laggard humanists can do it now, and although these technologies are changing scholarship, it's a question of scale (better! faster! more!) rather than of approach or technique or academic question, for the main. Technically facilitated tasks like updating websites, using and updating wikis, using social media: even the late majority of humanists can do it now. Online tools are available, such as Voyant, which allow you to do text analysis, and manipulate texts to see the underlying patterns: so the early majority of humanists can use these tools should they want to. But the most difficult, intellectual work of applying technology in the humanities still occurs before the chasm has been crossed, in the phase of innovation, and early adoption, where we are looking at the technologies that cross our path and saying "how can I use, or develop this tool for use, in my research?", much like those in the 1950s or 1960s who were coming across university mainframes and asking how best to apply that in the literary and linguistic arena. It's important to note, of course, that this wave of technology keeps on coming at us, and the place of where technology sits along the curve changes: 20 years ago, had you been making a website for your humanities project, you would have been an innovator, rather than a late majority, and the same holds for word processing 40 years ago. The technology keeps coming: we have to respond to 
this, innovate, adopt, and see what is useful or useable for, or used by, the majority of people in our discipline.

Now (and this is the most contentious thing I'm going to discuss in this paper, for those engaging who are dyed-in-the-wool Digital Humanists) one of the problems that we have as a movement is that we tend to get caught up and fixated upon a certain technological solution. For example, every DH program I've come across teaches XML, that technology which took over from SGML in the conference abstracts - as the best practice way to encode text. And there's no doubt that XML provides the framework with which we can both explore theoretically what it means to describe texts computationally, in such a way they retain the information in their printed or manuscript form, whilst also the means to build and test prototypes. But XML as a technological standard has been around for 16 years, and technology moves on, but $\mathrm{DH}$ does not seem to be doing so. In many ways, DH's relationship to XML is similar to the AI community's relationship with LISP: the means of computational expression in the language or format suit the questions which need to be asked by the field, so there is no need to use other technologies which come on stream, which may be more efficient from a computational point of view, as we explore what it means to work with our question in this computational way. And that's ok, but we should not be blind to the fact that technology is advancing all the time and, also, XML is not a technology that crossed the chasm: it may be in use for technical systems, it certainly underpins a lot of information systems in general use, but it is not one that you see a lot of the general populace using. This, in turn, means that DH has permanently hitched its wagon to an aging technology, which is hard to explain to others, including other non-XML humanists, whilst other things are happening in the technological world around us. Just something we have to watch out for, when building teaching programs, or looking at the scope of outputs in our field. We do not want to be left behind as the digital in digital humanities rolls on without us.

I find it useful to plot my research on the Innovation Curve, to see where what I am doing sits. So, the work on counting terms across a corpus - very much sits in the early majority nowadays, given the availability of free, relatively easy to use, online tools to do so. But the work on building an iPhone app to do this work is very much innovation: it took a lot of pure programming in a relatively new space to achieve it. The work in image processing I do is either innovation (we are publishing here in pure computer/engineering science venues, as well as in humanities venues, which I'm very proud of), or we adopt technologies our academic colleagues in the engineering sciences have generated and roll them out to a humanities or heritage application. Our work on user studies is something completely different though: here we are generally looking at how the majority of people are using an extant text, or (in the case of something like Transcribe Bentham, or QRator) we are conducting reception studies, where we innovate and build a technology, launch it, and study its uptake across the whole cycle. We can see, then a range of DH activity across the innovation cycle, but the majority of the work I do is certainly at the start of the innovation curve. Is this where DH sits? I like to think so, but more to the point, I'm confident it's where I sit best, when doing DH.

I need here to show you another curve, though. This time, the Gartner Hype Cycle ${ }^{37}$ which looks at how technologies are launched, mature, and are applied (so people know when to invest). The premise of this is that when technologies are first triggered, everyone thinks they are going to be the Next Big Thing, and so they reach "the peak of inflated expectations", before crashing 


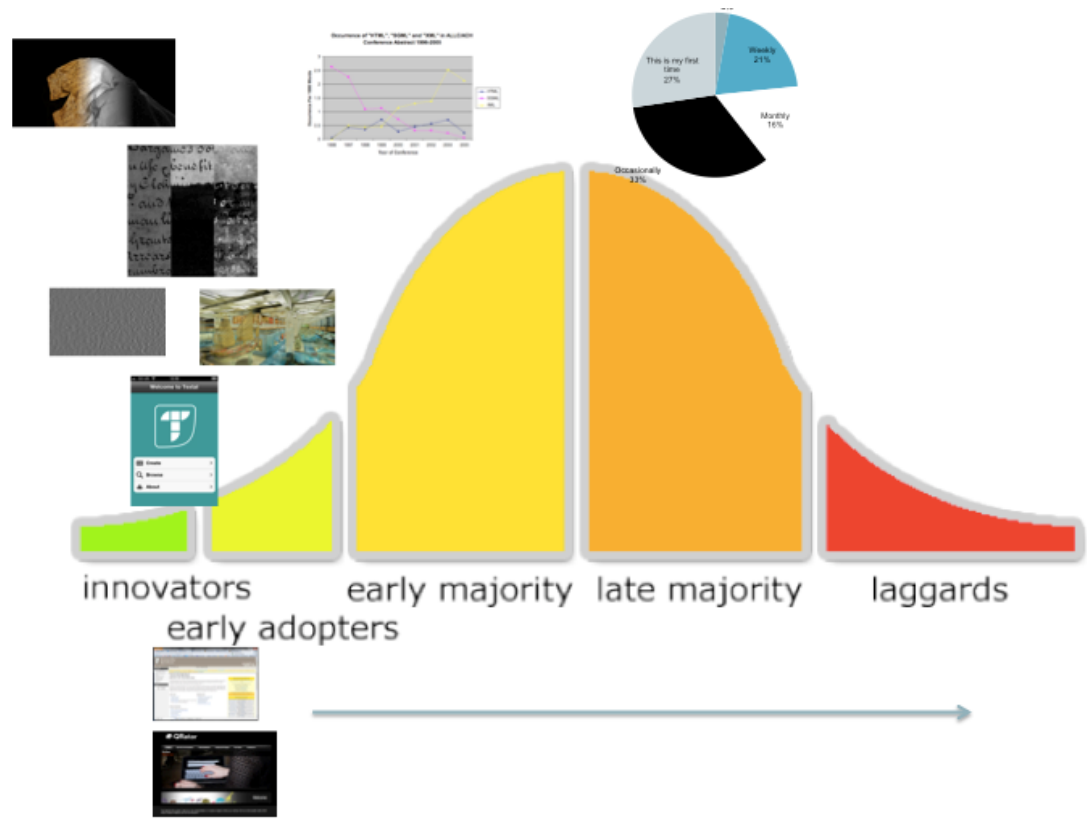

Fig. 1. The research and projects mentioned in the opening moments of this lecture, plotted on the Innovation Curve. Most sits squarely in the innovator or early adopter phase, whilst some tools (such as text analysis) are now available for the early majority. The study of users of large scale systems is actually the study of the habits of the majority of technology users as they use available technology in culture and heritage

down into a "trough of disillusionment" when those adopting them realise they are not that great at all. It is hard work to get technologies up the "slope of enlightenment" where useful, useable applications are found, and few technologies make it to the "plateau of productivity" where they become profitable. Despite its flaws and detractors ${ }^{38}$, it is a useful curve - 2014's predictions ${ }^{39}$ show Big Data right at the top of the peak, which chimes in with media coverage of how it will (or will not) solve everything ${ }^{40}$. So where would I put DH, if I had to as a movement, on this curve?

I would put it at the top. At the top of the Peak of Inflated Expectations. We have got a lot of pressure on us to prove our johnny-come-lately benefit to the world of academia, to demonstrate our worth, to show that the investment made in us over the past few years is worth it (whilst also bringing in further investments in research funding, to meet institutional expectations). After a peak, comes a crash, and we have to be prepared for the tide to turn and the backlash to begin, after the years of media hype and raised expectations. (Some would say that this backlash has already started, see position pieces by Fish (2011, 2012a, and 2012b) and Kirsch (2014) for examples of "is that it?" lit in DH - and Kirschenbaum (2014) and Worthey (2014) for parallel pieces that respond to these type of criticism. It is becoming a genre in itself ${ }^{41}$ ). So how - partly to assuage our critics, but mostly to ensure our work is worthwhile, continued, and embedded into the academy - do we get to the plateau of productivity of Digital Humanities?

First, I would argue that we have to understand our lineage: that the current manifestation of DH is a logical progression of qualitative methods used in the humanities for the past 500 years. That the current manifestation of DH is a logical progression of humans wondering what the potential is for applying computational methods 


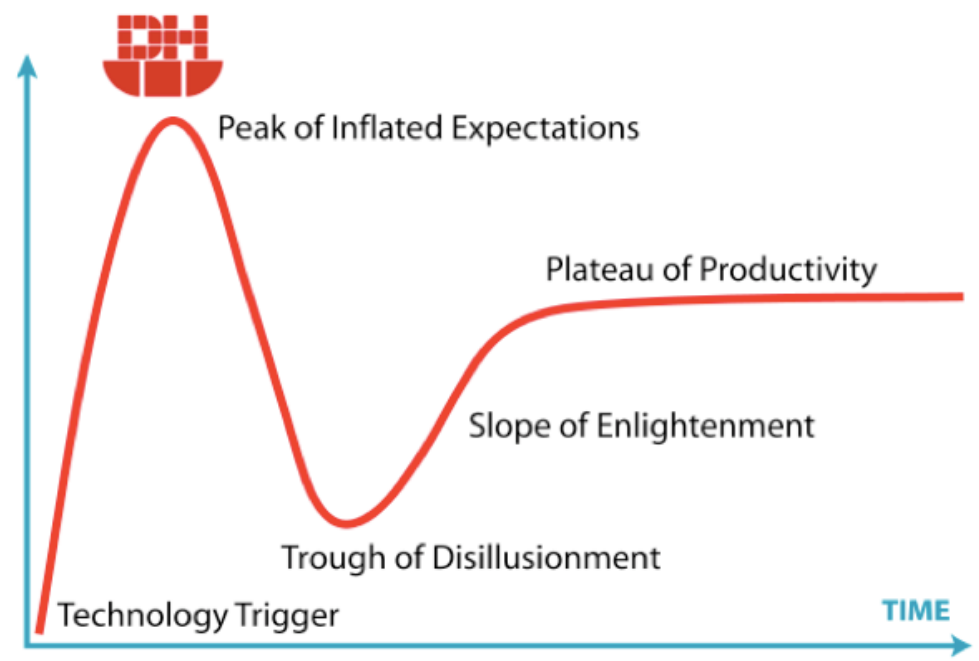

Fig. 2. The good ship Digital Humanities at the top of the peak of inflated expectations

to humanities problems, which has been going on in the digital space for the past 60 years. These combined trajectories are not going away, and despite what funding cuts and media backlash may come at us, it is the role of the digital humanist to understand and investigate how computers can be used to question what it means to be human, and the human record, in both our past and present society. Secure in our mission, we can carry on whatever the storm throws at us.

Second, I would argue we have to ignore naysayers who are unsure about this new Digital Humanities lark (and believe me, there are plenty, even in my own department of Information Studies) and just do good work. The way to demonstrate our worth is to demonstrate our worth through doing good work. We have to keep asking questions about computational methods, computational processes, and the potentials that they offer humanities scholars, as well as the pitfalls, to explore this changing information environment from the humanities viewpoint. It is not just about building websites, or putting information online, it is about innovating and adopting, and questioning while we build about the ramifications of doing this, the impact on the humanities, the issues using technology raises, and the answers it provides that you could not otherwise generate, to do good work in Digital Humanities. I realise this is very Calvinist of me but I do see that we have to be engaging with theories and questions of what is means to be doing this work in this way, as well as updating a website or creating a digital file. A continuation of what it means to be a humanities scholar, in the digital space.

When I look back over the variety and range of projects, publications, and outputs that I've worked on, either on my own, or as part of a team (there's a lot of teamwork that has gone on here) I'm firstly surprised at how much of it there is and the range of topics we've covered, and the opportunities we've pounced on. I see a body of work which explores various aspects of what it means to be applying digital technologies in the humanities space, and facilitates both those in engineering science and those in the humanities to explore issues which are important to them. I have learnt things along the way about the nature of interdisciplinary work, the nature of teams, the nature of the academic publishing and peer review process, the nature of the grant funding 
process, but I've written about that elsewhere ${ }^{42}$. There are things, also, that I am proud of that are physical rather than purely digital: over the last few years I'm most proud of building the UCL Multi-Modal digitisation suite, which is a shared space between the UCL Library Services, UCL Faculty of Arts and Humanities, and UCL Faculty of Engineering Science, providing means to both carry out, teach, and research digitisation practices, contributing to the infrastructure of UCL in a collaborative endeavour. But what I see here, as a common thread, is that the work I do tends to sit right at the beginning of the technology adoption cycle, aiding and abetting the application of technology within the arts, humanities, and heritage, and I'm comfortable with that. There's a strength in knowing your place, and your remit, and what you do best.

So the third reason for calling my paper "A Decade in Digital Humanities" is that I did not discuss which decade we were talking about, and it is time also to look towards the future, and what the next ten years holds for both $\mathrm{DH}$, as the field turns into a teenager, and for me, as I go into my next decade at UCL. I see an inevitable fragmentation of the $\mathrm{DH}$ community and DH focus - it was never conceived of as a homogenous entity anyway, and it is the nature of waves and swells that they will dissipate. We'll see (we are already seeing) more focussed groups of scholarly work around, say, Geographical Information Systems and literature, as people specialise and work on specific technologies and specific methods. The technology will keep coming, and it is up to individual humanities scholars to respond to what is appropriate to their research question: the effects of DH scholarship will continue to ripple out across the humanities as technologies go along the adoption cycle, and certain aspects of digital research will just become normal for humanities scholars, as time goes on.
But I do see that there will always be a place, right at the start of the technology innovation uptake curve, for specialists in Digital Humanities to sit, watching out for these changing and emerging technologies, setting up pilot projects to experiment with different aspects of these technologies, feeding back recommendations and the potential ramifications for other humanities and engineering scholars and those within the wider cultural and heritage sector, and exploring what is means to be doing humanities research in that area. I am happy to remain there, and I see that this will remain my place working with other humanists, and engineers and computer scientists, over the next decade. I am delighted to be a co-investigator on the doctoral training centre for Science and Engineering in the Arts Heritage and Archaeology, which is the EPSRC's largest ever investment in Heritage Science, and for the next 8 years we will be training up a range of doctoral students in this cross section of the arts, heritage, humanities, and engineering and conservation science. (Perhaps what I really do is Heritage Science, but that's another paper entirely, and DH has work to do with the Heritage Science community in future). We do have work to do, in keeping an eye to making sure people know about the successes, outputs, and impacts of DH work. Given the expectations foisted upon us, we have to learn to be more vocal about our objectives, our remit, and our results. It is our job to be thinking what it means to use digital technologies in humanities research. As a result, our insights can benefit a range of other fields, if we communicate them effectively.

Digital technologies are not going away any time soon: and although DH has had a rapid swell, it will remain essential that we investigate, use, and experiment with technologies over the coming decade. There is a new Companion to Digital Humanities coming out in late 2015, showing how the technologies used in humanities 
research have developed since the first edition (I am delighted to have written a chapter on our public engagement work for it). I have shown here that our uptake of technologies in the humanities is, and will continue to be, a moving target, and that as part of a longer trajectory of investigation into humanities methods, $\mathrm{DH}$ is a modern but necessary, and even inevitable, part of the Humanities, and even computational, landscape. I look forward to what adventures the next Decade in Digital Humanities holds. There is so much to do!

I have a few brief thanks to make - its quite a lick to go from probationary lecturer to full prof in ten years, and so I have to thank those who have supported me. Thanks go to my family up in Scotland for all their support, and my family of my own. I've been blessed with an amazing support network of friends, who have supported my enormously over this period. My first academic supervisor was Professor Seamus Ross, who kick started my interest in this area, and his support and interest at the start of my career really set me up for the work I do today. Likewise, my PhD supervisor Professor Alan Bowman remains a fantastic mentor. My other PhD supervisor, Professor Sir Mike Brady, made me promise (when I got my doctorate in engineering) not to go near any nuclear power stations or bridges, a promise I have kept. I've already mentioned that Professor Susan Hockey gave me my first academic job: but her work remains an inspiration on what is possible in computing in the arts and humanities. I work with an amazing team of people at UCLDH and I thank them for their input both for the centre and on our various projects. Special thanks go to Dr Rudolf Ammann, our designer at large.

But in this week of UCL's Festival of the Arts and Humanities, it is good to pause and see how embedded Digital Humanities research is now throughout college, and how much we work, in the Humanities, with those around us. The projects I've shown, albeit briefly, today, are carried out in league with various other faculties (UCLDH reports to both the Arts and Humanities and Engineering Faculties at UCL). Colleagues come from a range of different departments including not only those across the Arts Faculty, but the Bartlett Centre for Advanced Spatial Analysis (in the UCL Bartlett Faculty of the Built Environment), and across the UCL Faculty of Engineering (I have joint projects with Medical Physics, Computer Science, and Civil, Environmental, and Geomatic Engineering). We are dependent on input from both our colleagues in UCL Library Services, and UCL Museums and Collections, and work very closely with items in all the collections across college. The success of DH at UCL is then dependent on the institutional context we have here, and supportive institutional contexts for DH remain incredibly important as the field drives forward ${ }^{43}$. Digital Humanities is now embedded into college life at UCL, and in this week of the Festival of the Arts, my final thanks go to UCL as a community for its institutional support in encouraging us to ride the DH wave: for without being at UCL, my decade in digital humanities would have been completely different.

See Schreibman, Siemens, and Unsworth (2004) Ray Siemens(2013).

See Pannapacker (2011)

See Terras, Nyhan, and Vanhoutte (2013a) for an overview of how complex the issue of producing a single adequate definition of "Digital Humanities" is.

See Terras et al 2013 b.

For the themes named in the next paragraph I give examples of work I have published in these areas, although I remain aware that there is much other work by others that could be cited! 
6 This is a previously unpublished visualization of the occurrence of three terms (HTML, XML, and SGML) in conference abstracts in the major annual conference in my field between 1996 and 2005. Originally carried out as part of the analysis for Terras (2006) it finally became useful to show here.

See Terras et al 2013c.

See Terras (2006).

See Giacometti, Terras, and Gibson (Forthcoming 2014)

See Pal, Terras, Weyrich (2013).

See for example Warwick et al (2008) and Ross, Terras, and Motyckova (2012).

Causer and Terras (2014)

Ross et al (2013)

See Bod (2013)

T. W. (1579).

Boemus et al (1611).

Schleicher (1852).

Terras (2009)

See Menabrea (1842)

See Essinger (2014)

See Winter (1999) and Passarotti (2013)

See Winter (1999)

See Woodhead (1965)

See Brown (2009)

See Hockey (2000)

See Igarashi et al (2014)

See Terras (2006a) and Vanhoutte (2013).

See Pannapacker 2011 for a criticism.

See Warwick et al (2012) and Terras et al (2013d).

http://dh2014.org/more/contacts/

See Weingart (2014).

See Terras (2012a).

Frischer et al (2006), p.4.

Hayles (2012), p.59.

Maron and Pickle (2014)

Rogers 1962

See Gartner (2014).

See Aranda (2006).

Gartner (2013).

40 See CRN (2014) for an example of computer industry media hype, and Sunyer (2013) and Steadman (2013) for coverage of Digital Humanities and big data in leading news publications.

41 I collect blog posts about how people define DH - both for and against - over at http://blogs.ucl.ac.uk/definingdh/furtherreading/

$42 \quad$ See Terras (2012b)

43 See Maron and Pickle (2014).

\section{References}

Causer, Tim and Melissa Terras, (2014) 'Many hands make light work. Many hands together make merry work: transcribe Bentham and crowdsourcing manuscript collections. In Crowdsourcing Our Digital Heritage, Edited by M. Ridge. 57-88. Ashgate.

pinion Pages, New York Times, December 26 ${ }^{\text {th }}$, 2011. http://opinionator.blogs.nyCCtimes. com/2011/12/26/the-old-order-changeth/?_php=true\&_type=blogs\&scp $=1 \&$ sq $=$ Fish $\% 2001 d \% 20$ Order\&st $=$ cse\&_r $=0$

Fish, S. (2012a). "The Digital Humanities and the Transcending of Mortality," Opinion Pages, New York Times, January $9^{\text {th }}$ 2012. http://opinionator.blogs.nytimes.com/2012/01/09/the-digitalhumanities-and-the-transcending-of-mortality/?scp=1\&sq=Fish\%20transcending\&st=cse

Fish, S. (2012b). “Mind Your P's and B's: The Digital Humanities and Interpretation," Opinion Pages, New York Times, January 23 ${ }^{\text {rd }}$ 2012. http://opinionator.blogs.nytimes.com/2012/01/23/ mind-your-ps-and-bs-the-digital-humanities-and-interpretation $/$ scp $=1 \&$ sq $=$ Fish $\% 20$ mind\&st $=$ cse 
Frischer, B, Unsworth, J., Dwyer, A., Jones, A., Lancaster, L., Rockwell, G., Rosenzweig, R., Wells, S. (2006) "Summit on Digital Tools for the Humanities: Report on Summit Accomplishments" Report from Summit on Digital Tools for the Humanities, September 28-30, 2005, University of Virginia http://www.iath.virginia.edu/dtsummit/SummitText.pdf

Gartner (2013). “Gartner's 2013 Hype Cycle for Emerging Technologies Maps Out Evolving Relationship Between Humans and Machines". August $19^{\text {th }}$ 2013, http://www.gartner.com/newsroom/ $\mathrm{id} / 2575515$

Gartner (2014). “Interpreting Technology Hype” Methodologies, Hype Cycle. http://www.gartner. com/technology/research/methodologies/hype-cycle.jsp

Hayles, N. Katherine(2012). "How we think: transforming power and digital technologies" In Berry, D. (ed) (2012). “Understanding Digital Humanities”, Palgrave Macmillan. B. (2014). Computing: A Historical and Technical Perspective. Hoboom/article/117428/limits-digital-humanities-adamkirsch

Kirschenbaum, M. G. (2010). "What is Digital Humanities and What's It Doing in English Departments?” ADE Bulletin, 150. p 55-61.

Kirschembaum, M. (2014). “'What is 'Digital Humanities,' and Why Are They Saying Such Terrible Things about It?" In the Shadows of the Digital Humanities edited by Ellen Rooney and Elizabeth Weed. differences 25.1 (2014). Available at http://mkirschenbaum.wordpress. com/2014/04/24/new-essay-what-is-digital-humanities-and-why-are-they-saying-such-terriblethings-about-it/

Maron, N., and Pickle, S. (2014). "Sustaining the Digital Humanities Host Institution Support beyond the Start-Up Phase". Ithaka S+R, http://www.sr.ithaka.org/research-publications/sustainingdigital-humanities.

Menabrea, Luigi F. 1842. Notions sur la Machine Analytique de M. Charles Babbage. Bibliothèque Universelle de Genève, 41, 352-376. (Translation by Augusta Ada Lovelace published 1843 in Scientific Memoirs, 3).

Pal, K., Terras, M., and Weyrich, T., (2013) "3D Reconstruction for damaged documents: imaging of The Great Parchment Book", 2nd International Workshop on Historical Document Imaging and Processing (HIP'13), in conjunction with The 12th International Conference on Document Analysis and Recognition, ICDAR 2013, Washington DC. http://www.cvc.uab. es/ vfrinken/HIP2013/

Pannapacker, W. (2011). “'Big Tent Digital Humanities,' a View From the Edge, Part 1". The Chronicle of Higher Education, July $7^{\text {th }}$ 2011. http://chronicle.com/article/Big-Tent-DigitalHumanities/128434/

Passarotti, M. C. (2013). "One Hundred Years Ago. In Memory of Father Roberto Busa SJ." In: Proceedings of The Third Workshop on Annotation of Corpora for Research in the Humanities (ACRH-3), 12 ${ }^{\text {th }}$ December 2013, Bulgarian Academy of Sciences, Sofia, Bulgaria. p. 15-24.

http://www.bultreebank.org/ACRH-3/ACRH-3Proceeding.pdf

Rogers, E. M. (1962). Diffusion of innovations. New York: The Free Press.

Ross, C., Terras, M., Motyckova, V. (2012). Scholarly Information Seeking Behaviour in the British Museum Online Collection. In Hughes, L. (2012). Evaluating \& Measuring the Value, Use and Impact of Digital Collections. (pp. 85-102). London: Facet. 
Ross, C. Carnall, M., Hudson-Smith, A., Warwick, C., Terras. M. and Gray, S. (2013). "Enhancing Museum Narratives:Tales of Things and UCL's Grant Museum". In Farman, J. (Ed). Digital Storytelling and Mobile Media: Narrative Practices with Locative Technologies. Routledge. pp. 276-289.

Schleicher, A. (1852). Die formenlere der kirchenslawischen sprache, erklärend und vergleichend därgestellt. Bonn: H.B. König.

Terras, M. (2006a). "Disciplined: Using Educational Studies to Analyse 'Humanities Computing'." Literary and Linguistic Computing, Volume 21. 229- 246.

Terras, M. (2006b). Image to Interpretation: Intelligent Systems to Aid Historians in the Reading of the Vindolanda Texts". Oxford Studies in Ancient Documents. Oxford University Press.

Terras, M. (2009). "Potentials and Problems in Applying High Performance Computing for Research in the Arts and Humanities: Researching e-Science Analysis of Census Holdings". Digital Humanities Quarterly. http://www.digitalhumanities.org/dhq/vol/3/4/000070/000070.html Fall 2009

Terras, M. (2012a). "Quantifying Digital Humanities". Infographic. UCL Centre for Digital Humanities. http://www.flickr.com/photos/ucldh/6730021199/

Terras, M. (2012b). "Being the Other: Interdisciplinary work in Computational Science and the Humanities". In Deegan, M. and McCarty, W. (Eds) “Collaborative Research in the Digital Humanities". London, Ashgate. p. 213-230.

Terras, M., Nyhan, J., Vanhoutte, E., (2013a). “Defining Digital Humanities, a Reader.” Farnham, Ashgate. p. 119-156.

Terras, M., Priego, E., Liu, A., Rockwell, G., Sinclair, S., Hensler, C., and Thomas, L. (2013b). “The Humanities Matter!” Infographic, 4humanities.org/infographic.

Terras, M. .Gray, S., and Ammann, R. (2013c). “Textal: a text analysis smartphone app for Digital Humanities". Poster, Digital Humanities 2013, Nebraska, Lincoln. http://dh2013.unl.edu/abstracts/ab227.html

Terras, M. M., Nyhan, J., \& Vanhoutte, E. (2013d). Defining digital humanities: A reader. Ashgate.

T. W. (1579). A concordance or table made after the order of the alphabet, conteyning the principall both wordes \& matters, which are comprehended in the newe Testament. Imprinted at London, by Christopher Barker, Printer to the Queenes most excellent Maiestie.

Vanhoutte, E. (2013) "The Gates of Hell: History and Definition of Digital | Humanities | Computing.” In: Terras, M., Nyhan, J., Vanhoutte, E., (2013). “Defining Digital Humanities, a Reader.” Farnham, Ashgate. p. 119-156.

Warwick, C., Terras, M. M., \& Nyhan, J. (2012). Digital humanities in practice. London: Facet Publishing in association with UCL Centre for Digital Humanities.

Warwick,C. Galina, I., Terras, M., Huntington, P., and Pappa, N. (2008). "The Master Builders: LAIRAH research on good practice in the construction of digital humanities projects" Literary and Linguistic Computing 23(3), 383-396

Weingart, S. (2014). "The size of the DH world is expanding rapidly. Same trend holds for followers of @dhnow \& searches for DH on Google”. Tweet, https://twitter.com/scott_bot/ status/465264351494955008/photo/1

Winter, T. N. (1999). Roberto Busa, S.J., and the Invention of the Machine-Generated Concordance. DigitalCommons@University of Nebraska-Lincoln. 
Worthy, G. (2014). "Why are such terrible things written about DH? Kirsch v. Kirschenbaum" https://digitalhumanities.stanford.edu/why-are-such-terrible-things-written-about-dh-kirsch-vkirschenbaum

Woodhead, D. (1965). "Cambridge May Lead in Computing”. Cambridge Evening News, Friday September $24^{\text {th }}, 1965$, p. 21. Available at http://melissaterras.blogspot.co.uk/2014/05/roy-wisbey-andliterary-and-linguistic.html

\section{Десятилетие цифровых гуманитарных наук}

Мелисса Террас

Университетский колледж Лондонаг

Лондон, Соединенное Королевство

В статье рассматривается значение и развитие иифровых гуманитарных наук с примерами работ, опубликованных в различных областях иифровых гуманитарных наук. Проводится анализ использования данных технологий и их значение для гуманитарных наук. Даны рекомендации применения иифровых технологий, которые могут быть полезны в различных сферах гуманитарного сектора.

Ключевые слова: ицирровые гуманитарные науки, центр ицирровых гуманитарных технологий Университетского колледжа Лондона, инновационная кривая.

Научная специальность: 24.00.00 - культурология. 